\title{
Environmental Scanning Approach to Assess Innovation and Technology Transfer Performance of Construction Companies
}

\author{
Gökhan DEMiRDÖĞEN, Zeynep IŞIK
}

\begin{abstract}
In construction industry, environmental scanning approach is crucial for companies in strategy development since it informs of the potentials and the barriers of which occurrence is out of control due to its dynamic nature. Nowadays, innovation and technology transfer strategies of construction companies are governed by the changing environmental facts and competitiveness caused by the innovation based demands. This study investigates the effects of environmental factors on the innovation and technology transfer performance of companies by categorizing the factors as either business or general. For this purpose, Structural Equation Modelling (SEM) was used as the analysis method that would enable companies to see those effects were developed. The analysis of the results indicated that general environmental factors and business environmental factors had sequential effects on innovation and technology transfer performance of construction companies highlighting new entrepreneurs in the market and macroeconomic fluctuations.
\end{abstract}

Keywords: construction industry; innovation and technology transfer; performance assessment; Structural Equation Modelling (SEM)

\section{INTRODUCTION}

During the last decades increasing demands for high quality, energy efficiency, low cost etc., as well as regulations and specifications forced construction industry to rethink the strategies they implement for better performance. Accordingly, innovation and technology transfer methods transpired into the agenda of the construction professionals. The differentiations in construction material production, use of "Information and Communication Technologies (ICT)", innovative contracting and bidding strategies or new construction technologies were then seen as the principal drivers of competitiveness among rivals [1]. Therefore, company performance assessed basically using the financial measures or internal processes, was then turned to be assessed based on the intellectual assets and achievements of the company in terms of innovation and technology transfer activities that they held.

The effects of innovation and technology transfer strategies of the companies can be observed on a large scale through industrial performance and macroeconomics. However, accomplishments of innovation and technology transfers may not immediately have an effect on financial indicators. Instead, their effect on sustainable growth can be clearly seen. This is because an upturn or downturn in national economics can stop or accelerate their innovation and technology transfer activities [2]. Regulations and specifications play an important role in motivation of companies to develop innovation and technology transfer strategies since those strategies can be used as a tool to increase efficiency and eliminate economic crises that countries might suffer.

The construction industry has a significant share in national income of most of the developing countries. Therefore, it can be clearly assumed that innovative activities in the construction industry will contribute considerably to national economics [3]. The construction companies are subject to intense competition. In this case, they should tend towards new activity, product and service types [4]. In other words, the competitive environment in the industry, and customer requests, both push construction companies to adopt innovation and technology transfers.
Innovation and technology transfers in the construction industry not only contribute to countries' economies but also influence them positively in terms of social aspects. A decrease in construction costs enables more people to take advantage of construction services and products.

Construction technology includes construction methods, process, equipment and materials. The use of innovations or available technology in the construction industry is identified as a result of necessities arising at business and project levels, and decisions are made based on those requirements. This phenomenon was examined and it resulted in a few studies in the literature [5].

However, in the literature no study was found that investigates the effects of solely environmental factors on innovation and technology transfer performance of construction companies. However, some works in the literature do investigate the effects of just a very few environmental factors - alongside other factors - on innovation and technology transfer in construction industry. In an earlier research, in [6] the author considered factors influencing innovation such as "market structure, competition and high growth-rate in the market". In [7] the author indicated that "market and competition requirements, legal requirements, new technology and entrepreneurship opportunities" were all challenging factors and opportunities for construction companies. In [8] the authors defined the pressure caused by technological developments as an environmental factor. In [9] the authors stated that outdated materials affected the innovative activities of companies. In [10] the author investigated innovation factors in the organization network by examining some environmental factors such as "market appeal, regulations and government request". In [3] the authors studied customers' necessities and requests, as well as the regulations and standards, as factors that affect innovation. In [11] the authors indicated factors affecting innovation such as "environmental sustainability, climate change, globalization, and global competition and recession". In [12] the author investigated "technological developments, specifications and environmental sustainability" as factors effecting innovation. Moreover, other important factors in technology transfer were norms 
affected in formal and informal ways, as well as socialcultural factors.

Based on the literature review referred to above, it was seen that the studies related to innovation and technology transfers in the construction industry were limited and within the current studies, environmental and intracompany factors were dealt together. The major aim of environmental scanning is to adapt an organization's behaviour to the changing reality of the external world. It does not provide accurate predictions however instead it would provide better sensitized and prepared for the uncertain future. With this philosophy, this study conducting an environmental scanning approach, explores the effects of environmental factors on construction companies' innovation and technology transfer performance and proposes a model that companies could use to evaluate the successful adoption of innovation and technology transfer strategies by considering environmental factors. For this purpose, the external factors were determined based on a comprehensive literature review. Structural Equation Modeling (SEM) analysis method was adopted to determine the ratings of those factors and to construct the interrelationships in between. Thus, a questionnaire survey was carried out to collect data for SEM analysis. The data collected from the management levels of 52 construction companies were used for this purpose, and a model was developed using SEM, showing the ratings of the factors and the interrelationships in between.

\subsection{Environmental Scanning}

Environmental scanning approach was adopted to assess the nature of the environment, audit environmental influences and identify key competitive forces through structural analysis to identify opportunities and threats. It was assumed that only by this way the company would understand the factors effecting its innovation and technology transfer performance and therefore position itself in the industry accordingly and develop appropriate strategies. Thus, in the study, the factors affecting innovation and technology transfer performance of a construction company were categorized into three groups according to those based on the literature review.

\subsubsection{General Environmental Factors}

The general environmental factors that affect companies were found as V1 - Governmental incentives on research and innovation, V2 - Environmental (ecological) factors: Need to reduce energy consumption [13], V3 Macro economical fluctuations: Increasing need to innovation and technology transfer as a solution to macroeconomic fluctuations [14], V4 - Political stability for technological developments [15], V5 - Sociocultural factors: Innovation culture, V6 - Technological advancements by university industry collaborations [14], V7 - International relations [16], and V8 - Laws and regulations on $\mathrm{R} \& \mathrm{D}[15]$.

\subsubsection{Business Environmental Factors}

The business environmental factors were determined as V9-Client power: Existence of clients who have the power and willingness to implement innovations [17], V10-Boundary of market: Conventional structure of construction industry, difficulty of accepting innovation [3], V11-Innovation demand [18], V12-Compatibility of new developments to market structure [19], V13-Severity of competition between companies, V14-Supplier power [20], and V15- new entrepreneurs in the market [20].

\subsubsection{Indicators of Construction Company Technology Transfer and Innovation Performance}

The indicators were specified as V16 - Higher perceived value [21], V17 - Completion of project on budget with new developments [22], V18 - Completion of project on time with new developments [21, 22], V19 Competitive advantage among rivals [23], V20 Reputation/Company image, V21 - Productivity [24], V22 - Effect of innovation and transfer activities on financial indicators [25], V23 - Gains in learning and development via technological progress [26], and V24 -Satisfaction of customer/consumer [27].

\section{RESEARCH METHODOLOGY}

In this study, the Structural Equation Modelling (SEM) analysis method was used to determine the relationship between environmental factors and the performance of companies' innovation and technology transfer. This model investigates whether theoretical model based on the literature is supported and verified by the analysis of the data collected. Thus, the theoretical knowledge plays an important role in establishing the relationships between variables. Such theoretical knowledge, or models constructed using extensive theoretical knowledge, are tested and confirmed by factor analysis and path analysis. In this study, it was assumed that environmental factors affect construction companies' innovative and technological activities. To achieve this, the SEM method was used to estimate environmental factors and the relationship between them.

A questionnaire survey was carried out to perform analysis of the model under consideration. The questionnaire surveys were sent to 141 construction companies (All member companies in the Turkish Contractors Association) via e-mail and face-to-face meetings were conducted with higher management level respondents of 52 construction companies out of 141 members. The respond ratio to the survey was $37 \%$ which is statistically satisfactory. Of the construction companies filling out surveys, $85 \%$ were connected with building construction, $23 \%$ with industrial structures, $21 \%$ with transportation, $17 \%$ with infrastructure and $15 \%$ with water structures. The data collected were then analysed with Structural Equation Modelling (SEM) Analysis method by using EQS 6.2 Structural Equation Model software. 


\section{STRUCTURAL MODELLING ANALYSIS}

The SEM model was first suggested by Joreskog in 1969. One of the most important features of this model is that it enables non-measurable variables to be quantified using measurable variables. In this study, since the environmental factors cannot be directly measured, observed variables that will allow the measurement of environmental effects, are used. The SEM method consists of two models: "the measurement model" and "the structural model". Three different measurement models were shown in Fig. 1 in a triangle. The structural model in the study was shown in a rectangle. Measurement models were used to indicate the relationship between observable variables, which will allow measurement of environmental factors as well as the innovation and technology transfer indicators (latent variables), and their corresponding factor structures. The structural model, on the other hand, was used to show the causal relationship between environmental factors and the innovation and technology transfer indicators [28]. The suggested model consists of two dependent variables and one independent variable. The validity and reliability of the model analysed by the SEM method was presented below in detail.

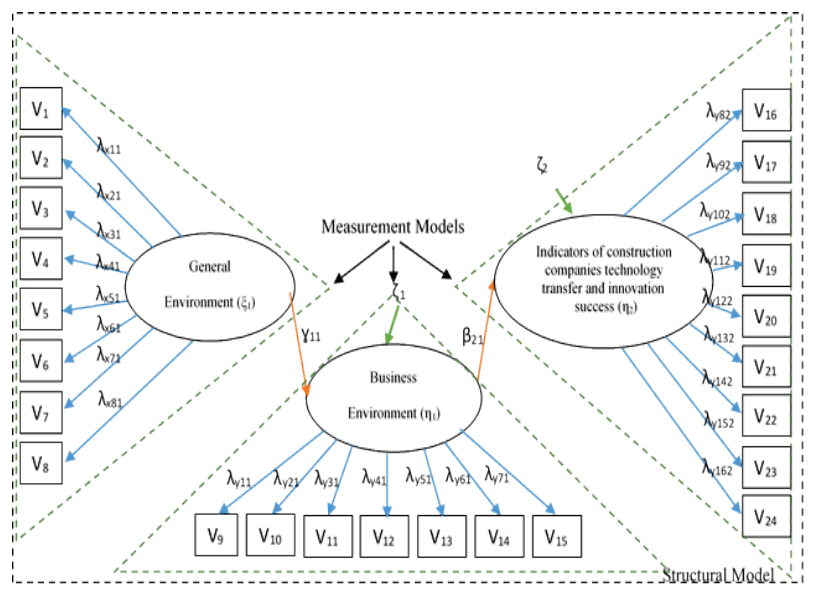

Figure 1 Research model considered in the analysis

\subsection{Confirmatory Factor Analysis}

Confirmatory Factor Analysis (CFA) was carried out to control the accuracy of relationships by considering the relationship between latent and observed variables [29]. CFA is of importance for acceptability of the model. In [30] the author categorized CFA into four steps: 1) model specification, 2) model estimation, 3) model evaluation and 4) model modification. The CFA of the proposed model was performed according to the analysis steps suggested by [30] without presenting the model modification step since it is used in case of an unverified model. These three steps were explained below.

\subsubsection{Model Specification}

In this step, hypotheses and equations for the theoretically suggested model were presented. The model was statistically identified, and the results obtained were evaluated.

Model hypotheses: Every model specified in the Structural Equation Model indicates theoretical hypotheses via one-way arrows between latent variables. In this study, the model was tested by changing the relationships between latent variables. The structural model yielding the best valid result was shown in Fig. 1. The most significant difference between structural and CFA models is that twoway covariance arrows are used instead of one-way arrows, indicating a causal relationship between latent variables. These covariance structures, before moving to the structural model, give information about the relationship between latent variables. In the literature, when CFA is conducted, two-way arrows that are used between factor structures can be made available between all factor structures, or the analysis can be conducted without any relationship between them.

In CFA, path coefficients between latent and observed variables are resolved by estimating covariance and vector matrices [30].

Hypotheses were based on the following estimations: The latent variable of the general environment estimates, variables between V1 to V8; the latent variable of business environment estimates, variables between V9 to V15; the latent variable of construction companies' innovation and technology transfer success estimates, variables between V16 to V24.

- Model statistical specification: The model estimation was carried out by transforming the relationships shown in Fig. 2. In this transformation, mathematical representation that was indicated by the authors [31] was used. The mathematical representation of measurement models including a dependent $(y)$ and an independent latent variable (x) are as shown as Eq. (1) and (2).

$y=\lambda_{y} \eta+\varepsilon$

where: $y-(p \times l)$ column vector of observed dependent variables; $\lambda_{y}-(p \times m)$ regression coefficient matrix of $y$ on $\eta ; \varepsilon-(p \times l)$ column vector of errors of measurement in $y$. And,

$x=\lambda_{x} \xi+\delta$

where: $x-(q \times l)$ column vector of observed independent variables; $\lambda_{x}-(p \times n)$ regression coefficient matrix of $x$ on $\xi ; \delta-(q \times l)$ column vector of errors of measurement in $x$.

Normalized results belonging to path coefficients and measurement errors obtained as a result of the confirmatory factor analysis, were shown in Tab.1.

- Model identification: Model parameter estimation was conducted by using the collected data. These estimated parameters were then used to estimate the population covariance matrix [30]. There are several limitations in model identification. The first one is that the number of data points must be greater than the number of parameters. The number of data points was calculated using Eq. (3).

Data points $=\frac{p(p+1)}{2}$

In the current study there were 300 data points, and the number of necessary estimated parameters was 51. Other criteria are that the regression coefficient between latent variable and observed variables should be taken as 1 ; there 
should not be any correlation between errors and indicator loadings should be only one factor. The criteria mentioned above were met in this study.

Table 1 Loadings according to results of confirmatory factor analysis

\begin{tabular}{|c|c|c|c|}
\hline Variable & $\lambda_{x}, \lambda_{y}$ & $\xi, \delta$ & $R^{2}$ \\
\hline $\mathrm{V}_{1}$ & 0,636 & 0,774 & 0,400 \\
\hline $\mathrm{V}_{2}$ & 0,778 & 0,629 & 0,605 \\
\hline $\mathrm{V}_{3}$ & 0,727 & 0,687 & 0,529 \\
\hline $\mathrm{V}_{4}$ & 0,567 & 0,824 & 0,322 \\
\hline $\mathrm{V}_{5}$ & 0,634 & 0,773 & 0,402 \\
\hline $\mathrm{V}_{6}$ & 0,533 & 0,846 & 0,285 \\
\hline $\mathrm{V}_{7}$ & 0,569 & 0,823 & 0,323 \\
\hline $\mathrm{V}_{8}$ & 0,554 & 0,832 & 0,307 \\
\hline $\mathrm{V}_{9}$ & 0,786 & 0,619 & 0,617 \\
\hline $\mathrm{V}_{10}$ & 0,325 & 0,946 & 0,106 \\
\hline $\mathrm{V}_{11}$ & 0,723 & 0,691 & 0,522 \\
\hline$V_{12}$ & 0,723 & 0,690 & 0,523 \\
\hline $\mathrm{V}_{13}$ & 0,636 & 0,771 & 0,405 \\
\hline $\mathrm{V}_{14}$ & 0,583 & 0,813 & 0,340 \\
\hline $\mathrm{V}_{15}$ & 0,944 & 0,329 & 0,891 \\
\hline $\mathrm{V}_{16}$ & 0,620 & 0,785 & 0,384 \\
\hline $\mathrm{V}_{17}$ & 0,751 & 0,660 & 0,564 \\
\hline $\mathrm{V}_{18}$ & 0,756 & 0,655 & 0,571 \\
\hline $\mathrm{V}_{19}$ & 0,789 & 0,615 & 0,622 \\
\hline $\mathrm{V}_{20}$ & 0,754 & 0,657 & 0,568 \\
\hline $\mathrm{V}_{21}$ & 0,738 & 0,675 & 0,545 \\
\hline $\mathrm{V}_{22}$ & 0,581 & 0,814 & 0,337 \\
\hline$V_{23}$ & 0,701 & 0,713 & 0,491 \\
\hline $\mathrm{V}_{24}$ & 0,581 & 0,814 & 0,338 \\
\hline
\end{tabular}

\subsubsection{Model Estimation}

After the model identification step to determine the model parameters, an estimation method in accordance with the data set should be selected to construct a population covariance matrix from the determined parameters. There are numerous estimation methods. The maximum likelihood method is the most common among these. However, the data should have a normal-distribution to apply this method. When the collected data was applied to the Kolmogorov-Smirnov and Shapiro- Wilk normality tests in SPSS software, the value of significance varied between 0,000 and 0,001. Consequently the data did not have a normal distribution; therefore, the Robust ML method was used for estimation. In [30] the author stated that the purpose of estimations in the SEM method is to minimize the difference between the model proposed by real data and the estimated population. [30] also presented Eq. (4), stating that when the estimation method was correctly selected, chi-square statistics of the model could be obtained by multiplying Eq. (4) with $(N-1)$.

$$
F=(s-\sigma(\Theta)) W(s-\sigma(\Theta))
$$

where: $s$ - the vector of the observed variables' covariance matrix; $\sigma-$ the vector of the estimated population' covariance matrix; $\Theta$ - symbol that indicates that $\sigma$ is derived from parameters; and $W$ - the matrix that shows difference between the data and estimated population.

\subsubsection{Model Evaluation}

This step uses the goodness of fit of the model obtained from statistical analysis. Widely used indices in literature are: the comparative fit index $(C F I)$, the root mean square error of approximation (RMSEA) and the non-normed fit index $(N N F I)$. Formulas related to these indices are calculated using Eq. $(5) \div(9)$.

$$
\tau_{\text {indep.model }}^{\prime}=\chi_{\text {indep.model }}^{2}-d f_{\text {indep.model }}
$$

where: $\chi^{2}$ indep.model - Chi-square of independence model; $d f_{\text {indep.model }}$ - Degrees of independence model freedom.

$$
\tau_{\text {est.model }}^{\prime}=\chi_{\text {est.model }}^{2}-d f_{\text {est.model }}
$$

where: $\chi^{2}$ est.model - Chi-square of estimated model; $d f_{\text {est.model }}$ - Degrees of estimated model freedom.

$C F I=1-\frac{\tau_{\text {est.model }}^{\prime}}{\tau_{\text {indep.model }}^{\prime}}$

estimatdRMSEA $=\sqrt{\frac{\tau_{\text {est.model }}^{\prime}}{N d f_{\text {est.model }}}}$

where: $N$ - sample size; $d f_{\text {est.model }}$ - Degrees of estimated model freedom.

$$
B N N_{\mathrm{k}}=\frac{\frac{F_{0}}{V_{0}}-\frac{F_{\mathrm{k}}}{V_{\mathrm{k}}}}{\frac{F_{0}}{V_{0}}-\frac{1}{N-1}}
$$

where: $F_{0}-$ Fit function of independence model; $N-$ sample size; dfest.model - Degrees of estimated model freedom; $V_{0}$ - Degrees of independence model freedom; $F_{\mathrm{k}}$ - Fit function of estimated model; $V_{\mathrm{k}}-$ Degrees of estimated model freedom.

Results obtained from $C F A$ were shown in Tab. 2. All indices obtained as a result of $C F A$ were within allowable limits.

\subsection{Reliability and Validity Analysis of Measurement Model}

To analyse the reliability and validity of measurement models, they were tested for content validity, scale convergent validity and discriminant validity [28]. Content validity, not requiring a statistical calculation, is a necessary condition to present observed and latent variables in line with the literature review.

Table 2 Evaluation results of confirmatory factor analysis

\begin{tabular}{|l|c|c|}
\hline \multicolumn{1}{|c|}{ Fit indices } & Allowable range & Overall \\
\hline$N N F I$ & 0 (no fit)-1(perfect fit) & 0,818 \\
\hline$C F I$ & 0 (no fit)-1(perfect fit) & 0,836 \\
\hline$R M S E A$ & $<0,1$ & 0,086 \\
\hline$\chi^{2} /$ degree of freedom & $<3$ & 1,381 \\
\hline
\end{tabular}

Scale reliability analysis provides internal consistency measurement. In other words, it shows to what extent the observed variables define corresponding latent variables. In this work, all factor loadings were evaluated for scale reliability analysis, and any value below 0,3 was identified. For reliability analysis, the Cronbach alpha value was considered. This value can be calculated using Eq. (10), 
and it should be equal to 0.7 for minimum conditions [32]. In [33] the author indicated that the reliability of the model cannot be measured by only the Cronbach alpha value, and alongside this, the reliability value of a composite score (RHO in figure) should also be measured. It is suggested that this value should be higher than 0,7 [34].

$$
\alpha=\frac{N p}{(1+p(N-1))}
$$

where: $\alpha$-Cronbach alpha value; $N$ - number of items; $p$ - mean inter-item correlation.

To fulfil convergent validity criteria, the observed variables should be statistically significant. Thus, all latent variables considered in the measurement models were evaluated to see whether they are significant at $\alpha=0,05$. In our study, all observed variables were significant at $\alpha=$ 0,05 .

Results of the Cronbach alpha value and reliability of a composite score were shown in Tab. 3. It was observed that the results obtained were within allowable limits.

The last analysis in the study was the discriminant validity test, which investigates to what extent observed variables belong to corresponding latent variables. The correlation between structures under latent variables was examined in this test. This correlation value should be a value under 0,90 [34]. In this study, the highest correlation values were $0,559,0,753$ and 0,686 for the general environment factor, the business environment factor and the construction companies' innovation and technology transfer success, respectively. As seen, all values were below 0,90 , fulfilling the last criterion.

\subsection{Structural Model}

Relationships between latent variables were investigated in the structural model. The representation of these relationships were indicated in the model via oneway arrows. In other words, structural model analysis hypotheses were either supported by the collected data or not. Summarizing hypotheses belonging to the structural model in this study verbally, produced the following statements.

- Indicators of construction companies' technology transfer and innovation success $=$ path coefficient $1^{*}$ Environmental Factors (Business Environment) + error terms 1

- $\quad$ Environmental Factors (Business Environment) = path coefficient 2* Environmental Factors (General Environment) + error terms 2

In the structural model analysis, since the estimation of factor loadings and structural coefficients contains the separation of the sample variance - covariance matrix, the term "covariance structural analysis" is extensively used. Variance-covariance terms are the matrices formed as a result of the latent independent variables' variancecovariance matrix, estimation errors in the structural model and covariance between them. Another variancecovariance matrix was constructed from measurement errors in the measurement models. The last covariancevariance matrix is the final matrix constructed using factor loadings from measurement models and structural coefficients from the structural model.

Table 3 Results of Cronbach alpha value (CAV) and reliability of a composite score for measurement models

\begin{tabular}{|c|c|c|c|}
\hline & Model variables & $C A V$ & $\mathrm{RHO}$ \\
\hline F1 & Environmental Factors (General Environment) & \multirow{9}{*}{0,83} & \multirow{9}{*}{0,84} \\
\hline V1 & $\begin{array}{l}\text { Governmental incentives on research and } \\
\text { innovation }\end{array}$ & & \\
\hline $\mathrm{V} 2$ & Environmental (ecological) factors & & \\
\hline V3 & Macro economical fluctuations & & \\
\hline $\mathrm{V} 4$ & Political stability for technological developments & & \\
\hline V5 & Sociocultural factors: Innovation culture & & \\
\hline V6 & $\begin{array}{l}\text { Technological advancements by university } \\
\text { industry collaborations }\end{array}$ & & \\
\hline V7 & International relations & & \\
\hline V8 & Laws and Regulations on R\&D & & \\
\hline $\mathrm{F} 2$ & Environmental Factors (Business Environment) & \multirow{8}{*}{0,85} & \multirow{8}{*}{0,87} \\
\hline V9 & Client power & & \\
\hline $\mathrm{V} 10$ & Boundary of market & & \\
\hline V11 & Innovation demand & & \\
\hline V12 & $\begin{array}{l}\text { Compatibility of new developments to market } \\
\text { structure }\end{array}$ & & \\
\hline V13 & Severity of competition between companies & & \\
\hline V14 & Supplier power & & \\
\hline V15 & New entrepreneurs in the market & & \\
\hline F3 & $\begin{array}{l}\text { Indicators of Construction Companies } \\
\text { Technology Transfer and Innovation Success }\end{array}$ & \multirow{10}{*}{0,89} & \multirow{10}{*}{0,89} \\
\hline V16 & Higher perceived value & & \\
\hline V17 & $\begin{array}{l}\text { Completion of project on budget with new } \\
\text { developments }\end{array}$ & & \\
\hline V18 & $\begin{array}{l}\text { Completion of project on time with new } \\
\text { developments }\end{array}$ & & \\
\hline V19 & Competitive advantage among rivals & & \\
\hline $\mathrm{V} 20$ & Reputation/Company image & & \\
\hline V21 & Productivity & & \\
\hline V22 & $\begin{array}{l}\text { Effect of innovational and transfer activities on } \\
\text { financial indicators }\end{array}$ & & \\
\hline V23 & $\begin{array}{l}\text { Gains in learning and development via } \\
\text { technological progress }\end{array}$ & & \\
\hline $\mathrm{V} 24$ & Satisfaction of customer/consumer & & \\
\hline
\end{tabular}

Like confirmatory factor analysis, the structural model consists of four steps: model specification, model estimation, model evaluation and model modification. In this study, factor structures in structural model were considered as stated in confirmatory factor analysis. The relations of factor structures were used in a way that general environment factors affect the business environment, and the business environment factors affect construction companies' innovation and technology transfer success. The robust maximum likelihood method was used for model estimation. Goodness of fit results for the final model and the normalized results was shown in Tab. 4 and 5 respectively.

Table 4 Evaluation results of structural analysis

\begin{tabular}{|l|c|c|}
\hline \multicolumn{1}{|c|}{ Fit indices } & Allowable range & Overall \\
\hline$N N F I$ & 0 (no fit)-1(perfect fit) & 0,794 \\
\hline$C F I$ & 0 (no fit)-1(perfect fit) & 0,814 \\
\hline$R M S E A$ & $<0,1$ & 0,092 \\
\hline$\chi^{2} /$ degree of freedom & $<3$ & 1,431 \\
\hline
\end{tabular}

Table 5 Loadings according to results of structural analysis

\begin{tabular}{|c|c|c|c|}
\hline Variable & $\begin{array}{c}\lambda_{x}, \lambda_{\mathrm{y}}, \gamma_{11}, \beta_{21} \\
\text { (Factor loadings) }\end{array}$ & $\begin{array}{c}\xi, \delta, \zeta_{1}, \zeta_{2} \\
\text { (Measurement errors) }\end{array}$ & $R^{2}$ \\
\hline $\mathrm{V}_{1}$ & 0,654 & 0,757 & 0,43 \\
\hline $\mathrm{V}_{2}$ & 0,760 & 0,650 & 0,58 \\
\hline $\mathrm{V}_{3}$ & 0,735 & 0,678 & 0,54 \\
\hline $\mathrm{V}_{4}$ & 0,580 & 0,815 & 0,34 \\
\hline $\mathrm{V}_{5}$ & 0,635 & 0,772 & 0,40 \\
\hline $\mathrm{V}_{6}$ & 0,519 & 0,855 & 0,27 \\
\hline
\end{tabular}


Table 5 Loadings according to results of structural analysis (continuation)

\begin{tabular}{|c|c|c|c|}
\hline \multirow{2}{*}{ Table 5 Loadings according to results of structural analysis (continuation) } \\
\hline $\mathrm{V}_{7}$ & $\begin{array}{c}\lambda_{x}, \lambda_{\mathrm{y}}, \gamma_{11}, \beta_{21} \\
\text { (Factor loadings) }\end{array}$ & $\begin{array}{c}\xi, \delta, \zeta_{1}, \zeta_{2} \\
\text { (Measurement errors) }\end{array}$ & $R^{2}$ \\
\hline $\mathrm{V}_{8}$ & 0,563 & 0,826 & 0,32 \\
\hline $\mathrm{V}_{9}$ & 0,553 & 0,833 & 0,31 \\
\hline $\mathrm{V}_{10}$ & 0,785 & 0,619 & 0,62 \\
\hline $\mathrm{V}_{11}$ & 0,342 & 0,940 & 0,12 \\
\hline $\mathrm{V}_{12}$ & 0,716 & 0,698 & 0,51 \\
\hline $\mathrm{V}_{13}$ & 0,737 & 0,676 & 0,54 \\
\hline $\mathrm{V}_{14}$ & 0,636 & 0,772 & 0,41 \\
\hline $\mathrm{V}_{15}$ & 0,591 & 0,807 & 0,35 \\
\hline $\mathrm{V}_{16}$ & 0,933 & 0,361 & 0,87 \\
\hline $\mathrm{V}_{17}$ & 0,605 & 0,797 & 0,37 \\
\hline $\mathrm{V}_{18}$ & 0,756 & 0,655 & 0,57 \\
\hline $\mathrm{V}_{19}$ & 0,757 & 0,653 & 0,57 \\
\hline $\mathrm{V}_{20}$ & 0,783 & 0,622 & 0,61 \\
\hline $\mathrm{V}_{21}$ & 0,772 & 0,635 & 0,60 \\
\hline $\mathrm{V}_{22}$ & 0,741 & 0,672 & 0,55 \\
\hline $\mathrm{V}_{23}$ & 0,575 & 0,818 & 0,33 \\
\hline $\mathrm{V}_{24}$ & 0,689 & 0,725 & 0,47 \\
\hline $\mathrm{F} 1-\mathrm{F} 2$ & 0,588 & 0,809 & 0,35 \\
\hline $\mathrm{F} 2-\mathrm{F} 3$ & 0,518 & 0,855 & 0,27 \\
\hline & 0,503 & 0,864 & 0,25 \\
\hline
\end{tabular}

After performing structural model analysis, all parameters of the model with factor loadings and path coefficients were determined as shown in Fig. 2.

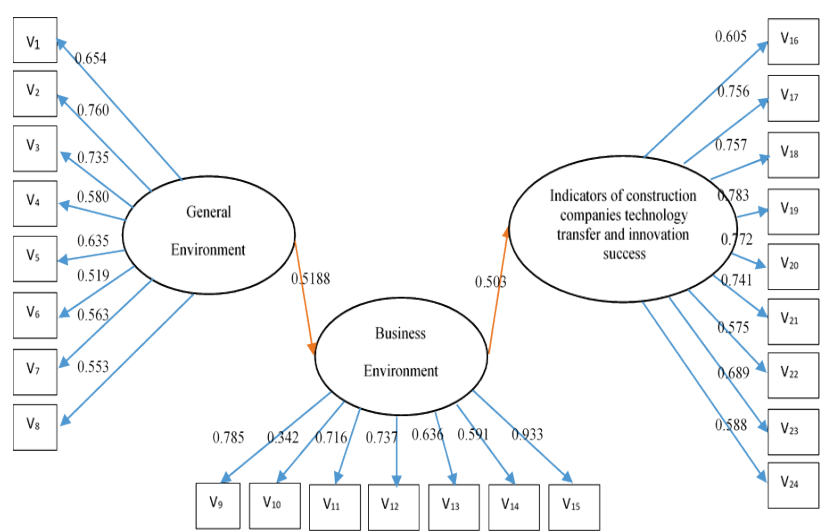

Figure 2 Final model according to the Structural Equation Modelling Method

\section{DISCUSSION}

The effects of environmental factors on construction companies' innovation and technology transfer success were examined. In literature, the authors [35] studied the effects of environmental factors as well as internal factors on innovation. They studied many industries, including the construction industry, and technological opportunity and compatibility of conditions were used as environmental factors. In this study, different than [35], environmental factors and their interrelationships were determined. Thus, environmental factors were divided into two groups: general and business environment. Analysis results indicated that general environment factors had direct impacts on construction companies' innovation and technology transfer. Observed variables used for measuring the general environment latent variable, and having the highest factor loading, were found to be ecological and macro-economic fluctuation factors as 0,760 and 0,735 respectively. The effects of ecological factors on innovation and technology transfer can be explained by the fact that ecological regulations trigger innovative activities, and companies place more importance on innovations [36]. The relationship between macro economical fluctuations and innovation and technology transfer was explained by the authors in [37]. The study stated that small-scale innovative companies dealing with innovation and technology transfer are of importance in absorbing macro-economical fluctuations. Therefore, policies developed by the government in this regard will pave the way for innovations in the sector.

Another result drawn from analyses was that the business environment had direct effects on construction companies' innovation and technology transfer. General environment factors supported these effects, as well. New entrepreneurs in the market and client power were found to be variables having the highest factor loading as 0,933 and 0,785 respectively, among variables aligned under business environment factors. New entrepreneurs in the market cause pressure on existing companies to either aggressive attitude to new entrepreneurs not to enter market or preserve their existing market share. In these circumstances, companies in the market try to differentiate by adopting innovative and technology transfer activities, encouraging these activities. Based on analysis results, the variable having the second highest factor loading was found to be client power. In [38] the author indicated that one of the important factors in developing innovative infrastructure is client.

Results of the study showed that all innovation and technology transfer indicators of construction companies were significant. The variables having the highest factor loadings were determined as competitive advantage and company reputation with factor loadings as 0,783 and 0,772 respectively. In [39] the authors investigated development and diffusion of technical innovations in construction industry and stated that companies must follow innovation and technology transfer activities in construction industry in order to save their competitive position in the market.

As another finding of the study, basically, company reputation was a significant outcome of the companies' competitive advantage acquisition endeavour. As was mentioned before, innovation and technology transfer activities were used for sustaining or increasing companies' competitiveness. Therefore, as it was found out in this study, the reputation was reflection of development and effective use of innovation for companies [3].

\section{CONCLUSION}

Adopting environmental scanning approach, it was hypothesized in this study that the company would understand the opportunities and threats and accordingly develop its strategies just by scanning its environment appropriately. Secondly it was hypothesized that there is a mutual interrelationship between the strategies of a company related with its innovation and technology transfer activities and the environmental facts effecting the company itself. Thus, this study investigated the effects of environmental factors on construction companies' innovation and technology transfer performance indicators. As a result of a comprehensive literature review, environmental factors were determined and categorized into two groups such as general and business environment factors; factor structures and relationships were analysed using the Structural Equation Modelling (SEM). The 
model constructed in the study, as opposed to other studies in literature, dealt only with environmental factors, and also differed from others in terms of being paired with innovation and technology transfer activities. It was observed that the suggested model met all verification criteria depicted in the literature. It was determined that general environment factors had indirect impacts but business environment factors had direct impacts on construction companies' innovation and technology transfer performance indicators. Moreover, the factor structures considered were incentive components for construction companies' innovation and technology transfer performance.

The model revealed that determination of the effects of environmental factors and strategies that are going to be developed according to those dynamic factors will enhance construction companies' innovation and technology transfer goals. Also the model provided opportunities in understanding reflection of environmental factors to company, showing problems and an area that needs solutions and improvements, measuring equivalent corporate investments, setting realizable innovation and technology transfer goals and benchmarking company's innovation and technology transfer activities with rivals. Therefore results of the study would be beneficial for researchers in extending innovation and technology transfer literature from the perspective of construction industry whereby it would provide concrete facts to construction practitioners in terms of innovation and technology transfer strategies of their companies.

Further studies can be implemented by discriminating type of construction fields and stakeholders. By this way, stakeholders' responsibility and performance within innovation and technology transfer activities can be identified according to each construction type. Moreover, effects of model that consider all environmental and internal factors can be investigated on construction industry performance.

\section{REFERENCES}

[1] Duarte, D. L. \& Snyder, N. T. (2006). Mastering virtual teams: Strategies, tools, and techniques that succeed. John Wiley \& Sons.

[2] Becker, S. O. \& Egger, P. H. (2013). Endogenous Product Versus Process Innovation and A Firm's Propensity to Export. Empirical Economics, 44, 329-354. https://doi.org/10.1007/s00181-009-0322-6

[3] Blayse, A. M. \& Manley, K. (2004). Key Influences on Construction Innovation. Construction Innovation, 4, 143154. https://doi.org/10.1108/14714170410815060

[4] Tatum, C. B. (1989). Managing for Increased Design and Construction Innovation. J. Manage. Eng., 5(4), 385-399. https://doi.org/10.1061/(ASCE)9742-597X(1989)5:4(385)

[5] Ozorhon, B., Abbott, C., \& Aouad, G. (2014). Integration and Leadership as Enablers of Innovation in Construction: A case study. Journal of Management in Engineering, 30, 256263. https://doi.org/10.1061/(ASCE)ME.1943-5479.0000204

[6] Tatum, C. B. (1986). Potential Mechanisms for Construction Innovation. J. Constr. Eng. Manage., 112, 178-191. https://doi.org/10.1061/(ASCE)0733-9364(1986)112:2(178)

[7] Tatum, C. B. (1987). Process of innovation in construction firm. Journal of Construction Engineering and Management, 113, 648-663.

https://doi.org/10.1061/(ASCE)0733-9364(1987)113:4(648)
[8] Mitropoulos, P. \& Tatum, C. B. (2000). Forces driving adoption of new information technologies. Journal of Construction Engineering and Management, 126, 340-348. https://doi.org/10.1061/(ASCE)0733-9364(2000)126:5(340)

[9] Seaden, G., Guolla, M., Doutriaux, J., \& Nash, J. (2003). Strategic decisions and innovation in construction firms. Construction Management and Economics, 21, 603-612. https://doi.org/10.1080/0144619032000134138

[10] Bossink, B. A. G. (2004). Managing Drivers of Innovation in Construction Networks. Journal of Construction Engineering and Management, 130, 337-345. https://doi.org/10.1061/(ASCE)0733-9364(2004)130:3(337)

[11] Boddy, S. \& Abbott., C. (2010). Review of CIB Collected Outlook Reports. Rotterdam, CIB.

[12] Ozorhon, B. (2012). Analysis of Construction Innovation Process at Project Level. Journal of Management in Engineering, 29, 455-463. https://doi.org/10.1061/(ASCE)ME.1943-5479.0000157

[13] Bansal, P. \& Roth, K. (2000). Why Companies go Green: a Model of Ecological Responsiveness. Academy of Management Journal, 43, 717-736. https://doi.org/ 10.2307/1556363

[14] Arditi, D., Koksal, A., \& Kale, S. (2000). Business Failures in the Construction Industry. Engineering, Construction and Architectural Management, 7, 120-132. https://doi.org/10.1108/eb021137

[15] El-Sayegh, S. M. (2008). Risk Assessment and Allocation in the UAE Construction Industry. International Journal of Project Management, 26, 431-438. https://doi.org/10.1016/j.jproman.2007.07.004

[16] Friedman, J., Gerlowski, D. A., \& Silberman, J. (1992) What Attracts Foreign Multinational Corporations? Evidence from Branch Plant Location in the United States. Journal of Regional Science, 32, 403-418. https://doi.org/10.1111/j.1467-9787.1992.tb00197.x

[17] Chan, A. P. C., Ho, D. C. K., \& Tam, C. M. (2001). Design and Build Project Success Factors: Multivariate Analysis. Journal of Construction Engineering and Management, 127, 93-100. https://doi.org/10.1061/(ASCE)0733-9364(2001)127:2(93)

[18] Porter, M. E. (2011). Competitive advantage of nations: creating and sustaining superior performance. Simon and Schuster.

[19] Chiang, Y., Tang, B., \& Leung, W. (2001). Market Structure of the Construction Industry in Hong Kong. Construction Management and Economics, 19, 675-687. https://doi.org/10.1080/01446190110067046

[20] Porter, M. E. (2008). The five competitive forces that shape strategy. Harvard Business School Publishing.

[21] Bresnen, M. \& Marshall, N. (2000). Partnering in construction: a critical review of issues, problems and dilemmas. Construction Management and Economics, 18, 229-237. https://doi.org/10.1080/014461900370852

[22] Gann, D. M. (2000). Building innovation: Complex construct in a changing world. Thomas Telford, London. https://doi.org/10.1680/bicciacw.25967

[23] Lim, J., Schultmann, F., \& Ofori, G. (2010). Tailoring Competitive Advantages Derived from Innovation to the Needs of Construction Firms. J. Constr. Eng. Manage., 136, 568-580. https://doi.org/10.1061/(ASCE)C0.1943-7862.0000151

[24] Crespi, G. \& Zuniga, P. (2011). Innovation and Productivity: Evidence from Six Latin American Countries. World Development, 40, 273-290. https://doi.org/10.2139/ssrn.1818752

[25] Tidd, J. (2011). Innovation Management in Context: Environment, Organization and Performance. International Journal of Management Reviews, 3, 169-183. https://doi.org/10.1111/1468-2370.00062

[26] Fu, X., Pietrobelli, C., \& Soete, L. (2011). The Role of Foreign Technology and Indigenous Innovation in the 
Emerging Economies: Technological Change and Catchingup. World Development, 39, 1204-1212. https://doi.org/10.1080/14765284.2011.618590

[27] Zhang, H., Ko, E., \& Lee, E. (2013). Moderating Effects of Nationality and Product Category on the Relationship between Innovation and Customer Equity in Korea and China. J Prod. Innov. Manag,. 30, 110-122. https://doi.org/10.1111/j.1540-5885.2012.00990.x

[28] Su, Y. \& Yang, C. A (2010). Structural equation model for analyzing the impact of ERP on SCM. Expert Systems with Applications, 37, 456-469. https://doi.org/10.1016/j.eswa.2009.05.061

[29] Sohn, S. Y., Kim, H. S., \& Moon, T. H. (2007). Predicting the financial performance index of technology fund for SME using structural equation model. Expert Systems with Applications, 32, 890-898. https://doi.org/10.1016/j.eswa.2006.01.036

[30] Ullman, J. B. (2006). Structural equation modeling: Reviewing the basics and moving forward. Journal of personality assessment, 87, 35-50. https://doi.org/10.1207/s15327752jpa8701_03

[31] Fornell, C. \& Larcker, D. F. (1981) Structural equation models with unobservable variables and measurement error: Algebra and statistics. Journal of marketing research, 382388. https://doi.org/10.2307/3150980

[32] Nunally, J. (1978). Psychometric Theory. McGraw-Hill: New York, NY.

[33] Raykov, T. (1997). Estimation of composite reliability for congeneric measures. Applied Psychological Measurement, 21, 173-184. https://doi.org/10.1177/01466216970212006

[34] Hair, Jr. J. F., Anderson, R. E., Tatham, R. L., \& Black, W. C. (1998). Multivariate data analysis. Prentice-Hall: Englewood Cliffs, N.J.

[35] Jurado, J., Gutiérrez-Gracia, A., Fernández-de-Lucio, I., \& Manjarrés-Henríquez, L. (2008). The Effect of External and Internal Factors on Firms' Product Innovation. Research policy, 37, 616-632. https://doi.org/10.1016/j.respol.2008.01.001

[36] Jaffe, A. B. \& Palmer, K. (1997). Environmental Regulation and Innovation: a Panel Data Study. Review of Economics and Statistics, 79, 610-619. https://doi.org/10.1162/003465397557196

[37] Audretsch, D. B., Lehmann, E. E., \& Wright, M. (2014). Technology Transfer in Global Economy. J. Technol. Transf., 39, 301-312. https://doi.org/10.1007/s10961-012-9283-6

[38] Winch, G. (1998). Zephyrs of Creative Destruction: Understanding the Management of Innovation in Construction. Building Research \& Information, 26, 268279. https://doi.org/10.1080/096132198369751

[39] Gambatese, J. A. \& Hallowell, M. (2011). Enabling and measuring innovation in the construction industry. Construction Management and Economics, 29, 553-567. https://doi.org/10.1080/01446193.2011.570357

\section{Contact information:}

Gökhan DEMIRDÖĞEN, Research Assistant

Yildiz Technical University,

Department of Civil Engineering,

Construction Management Division,

Davutpaşa Mah. Davutpaşa Caddesi B-BLOK Z-59

34220 Esenler/istanbul, Turkey

E-mail: gokhand@yildiz.edu.tr

\section{Zeynep IŞIK, PhD, Associate Professor}

(Corresponding author)

Yildiz Technical University,

Department of Civil Engineering,

Construction Management Division,

Davutpaşa Mah. Davutpaşa Caddesi B-BLOK Z-59

34220 Esenler/istanbul, Turkey

E-mail: zeynep@yildiz.edu.tr 